Int. J. Dev. Biol. 61: 749-761 (2017)

doi: $10.1387 / \mathrm{ijdb} .170153 \mathrm{sc}$

\title{
The origin of dopaminergic systems in chordate brains: insights from amphioxus
}

\author{
ELISABETH ZIEGER ${ }^{1}$, THURSTON C. LACALLI*,2, MARIO PESTARINO ${ }^{3}$, MICHAEL SCHUBERT ${ }^{1}$ \\ and SIMONA CANDIANI*,3

\begin{abstract}
${ }^{1}$ Sorbonne Universités, UPMC Université Paris 06, CNRS, Laboratoire de Biologie du Développement de Villefranche-surMer, Observatoire Océanologique de Villefranche-sur-Mer, Villefranche-sur-Mer, France, ${ }^{2}$ Biology Department, University of Victoria, Victoria, BC, Canada and ${ }^{3}$ Laboratory of Developmental Neurobiology, DISTAV, University of Genova, Genova, Italy
\end{abstract}

\begin{abstract}
The basic anatomy of the central nervous system (CNS) is well conserved within the vertebrates and differs in significant ways from that of non-vertebrate chordates. Of the latter, amphioxus is of special interest, being the best available stand-in for the basal chordate condition. Immunohistochemical and gene expression studies on the developing CNS of amphioxus embryos and larvae are now sufficiently advanced that we can begin to assign specific neurotransmitter phenotypes to neurons identified by transmission electron microscopy (TEM), and then compare the distribution of cell types to that in vertebrate brains. Here, by monitoring tyrosine hydroxylase (TH) transcripts and protein, along with serial TEM, we identify a population of catecholaminecontaining neurons in the anterior nerve cord of amphioxus larvae and describe their pattern of synaptic inputs and outputs. Inputs parallel those to the large paired neurons that control the larval escape response, suggesting that the TH+ system functions as an accessory excitatory and perhaps modulatory pathway in larval locomotion, with the added feature of recruiting an assortment of additional interneurons to the circuitry. The TH+ cells probably contain either L-DOPA or dopamine, and correspond closely with a cell population known from previous work on adult amphioxus to be dopaminergic. This population lies in a CNS domain now thought to comprise a combined vertebrate diencephalon plus mesencephalon, the implication being that dopaminergic nuclei in both of these brain regions could derive from a single dien-mesencephalic population in the last common ancestor of amphioxus and vertebrates.
\end{abstract}

KEY WORDS: dien-mesencephalon, evolution, serial transmission electron microscopy, tyrosine hydroxylase

\section{Introduction}

The cephalochordate amphioxus (Branchiostoma) is now considered the closest living proxy for the ancestral chordate condition, and as such is an organism of considerable interest from a comparative and evolutionary perspective (Holland et al., 2013; Holland 2015). This is especially true for studies of the organization and circuitry of the central nervous system (CNS), as the expression patterns of developmentally important genes reveal that regional patterning along the anteroposterior axis of the CNS, including the brain, is highly conserved and comparable to that of vertebrates (Holland and Holland 1999; Holland et al., 2013). This makes amphioxus valuable as a model for early CNS development, and means the
Abbreviations used in this paper: $\mathrm{ADB}$, anterior dorsal bipolar neuron; $\mathrm{AX}$, axial fiber; cdb, central descending bundle; $\mathrm{CF}$, rostral core fiber; CN, commissural neuron; DA, dopamine or dopaminergic neurons/fibers; Di-Mes, dien-mesencephalon (excludes the prethalamus); DN, dorsal nerve; DT, dorsal tract; ESC, epithelial sensory cell; GABA, $\gamma$-aminobutyric acid; GS, gill slit; lab, left ascending bundle; INF, infundibular cells; IPN, ipsilateral projection neuron; $\mathrm{IsO}$, isthmic organizer; L-DOPA, 3,4-dihydroxy-L-phenylalanine; LMB, lamellar body; LPN, large paired neuron; MLR, mesencephalic locomotor region; MP, multipolar neuron; NP, neuropore; $\mathrm{P}$, proboscis; $\mathrm{pDA}$, putative dopaminergic or dopaminergic-related neurons/fibers; PIN, parainfundibular neuron; PMC, primary motor center; POP, pre-oral pit; PPN, preinfundibular projection neuron; PS, pigment spot; RN, rostral nerve; SDF, second-order neuron with descending fibers; T, trunk; TGN, tegmental neuron; $\mathrm{TH}$, tyrosine hydroxylase or tyrosine hydroxylase-containing neuron; upb, upper paraxial bundle; ZLI, zona limitans intrathalamica.

\footnotetext{
*Address correspondence to: Simona Candiani. Laboratory of Developmental Neurobiology, DISTAV, University of Genova, Viale Benedetto XV 516132 , Genova, Italy. Tel: +39 (10) 353-8051. Fax: +39 (10) 353-8226. E-mail: candiani@unige.it iD http://orcid.org/0000-0002-4453-5475 - or

Thurston C. Lacalli. Biology Department, University of Victoria, Victoria, BC, V8W-3N5, Canada. Tel: +1 (250) 721-7095. Fax: +1 (250) $721-7120$.

E-mail: lacalli@uvic.ca (iD) http://orcid.org/0000-0003-3123-7062
}

Supplementary Material (one movie) for this paper is available at: http://dx.doi.org/10.1387/ijdb.170153sc

Submitted: 3 July, 2017; Accepted: 11 July, 2017.

ISSN: Online 1696-3547, Print 0214-6282

(c) 2017 UPV/EHU Press

Printed in Spain 
development of early brain circuits can, in principle, be studied in a context that is far less complex than in any vertebrate.

Here we report on a distinctive cluster of cells in the anterior nerve cord of young larvae of two amphioxus species ( $B$. lanceolatum and $B$. floridae) identified using probes and antibody for tyrosine hydroxylase ( $\mathrm{TH})$ transcripts and protein, respectively. $\mathrm{TH}$ is responsible for converting tyrosine to L-DOPA, which can act as a neurotransmitter in its own right. L-DOPAergic neurons have been described, for instance, in the dorsal vagal complex and hypothalamus of vertebrates (Björklund and Dunnett 2007; Misu et al., 2003; Misu and Goshima 2006). Alternatively, L-DOPA can be transformed into other catecholamine neurotransmitters, including dopamine (DA), adrenalin, and noradrenaline (Daubner et al., 2011). Amphioxus is known to possess both vertebrate- and invertebrate-type D1-like and D2-like dopamine receptors (Candiani et al., 2005; Burman and Evans 2010, Bayliss and Evans 2013), and among the DA-containing neurons described from adult amphioxus by Moret et al. (2004), there is a prominent group (their Population 1) positioned dorsally, near the anterior end of the nerve cord, whose location corresponds closely with that of our $\mathrm{TH}+$ cells. In contrast, Moret et al. (2004) found no evidence for significant amounts of noradrenalin in amphioxus tissues, an indication that amphioxus lacks the adrenergic systems found in vertebrates.

We have now identified the TEM counterparts of our TH+ cluster and reconstructed both the cells and their projections from serial sections. The cells' location corresponds precisely with Population 1, supporting a provisional assignment to that neuronal group, and consistent with our early-stage cells being the first of that group to differentiate. Unlike the situation in the adult, we have so far been unable to demonstrate the presence of DA itself in larval neurons, but there are both technical and developmental reasons for this, not least that individual neurons can change their transmitter during development, a form of transmitter plasticity that can occur in catecholaminergic systems, including those using dopamine (Ugrumov 2013, Borodinsky and Belgacem 2016). In the comparative section of this paper, we therefore provisionally treat our $\mathrm{TH}+$ cells as either members of Population 1 or precursors to it, and examine what this may mean from a comparative neuroanatomical and functional standpoint.

To be more specific, having data on young larvae clarifies the positioning of both our $\mathrm{TH}+$ cell cluster and Population 1 relative to key morphological and molecular landmarks. DA nuclei in the vertebrate brain are located in the diencephalon and anterior midbrain, bridging between the two in some instances, and in the hypothalamus (Smeets and González 2000; Yamamoto and Vernier 2011). Identifying the precise amphioxus homolog of each of these regions is complicated by the absence in amphioxus of two key signaling centers that serve as landmarks in the vertebrate brain, the zona limitans intrathalamica and isthmic organizer (Castro et al., 2006; Holland et al., 2013). However, from the recent study by Albuixech-Crispo et al. (2017), it now appears that the amphioxus homologs of the caudal forebrain (i.e. most of the diencephalon) and mesencephalon are specified as a single unit, and this is where both our $\mathrm{TH}+$ cell cluster and Population 1 neurons are located. This implies that vertebrate DA nuclei in both regions could derive from a single, ancestral dien-mesencephalic population similar to that in amphioxus. Some implications are considered, including the role DA may play in establishing basal locomotory circuits within the brain, and in the development and functioning of neural circuits more generally.

\section{Results}

\section{TH $m$ RNA expression (B. lanceolatum)}

Transcripts of $B$. lanceolatum $T H$ were detected by whole mount in situ hybridization starting from the late neurula stage at $36 \mathrm{hpf}$ (hours post fertilization), when expression is visible in a small cluster of two to three dorsolateral cells in the posterior cerebral vesicle (Fig. 1A,B), increasing to four to five cells by 108 hpf (Fig. $1 \mathrm{C}-\mathrm{G})$. The cells are localized in the dorsolateral wall of the cerebral vesicle, just anterior and dorsal to the lamellar body. A similar staining pattern has also been documented in $B$. floridae larvae (Candiani et al., 2005), indicating that this $\mathrm{TH}+$ cluster is well conserved between the two species.

\section{Cellular details revealed by tyrosine hydroxylase protein immunohistochemistry (B. lanceolatum)}

The distribution of $\mathrm{TH}$ protein was examined using a polyclonal antibody against TH, combined with confocal microscopy (Fig.
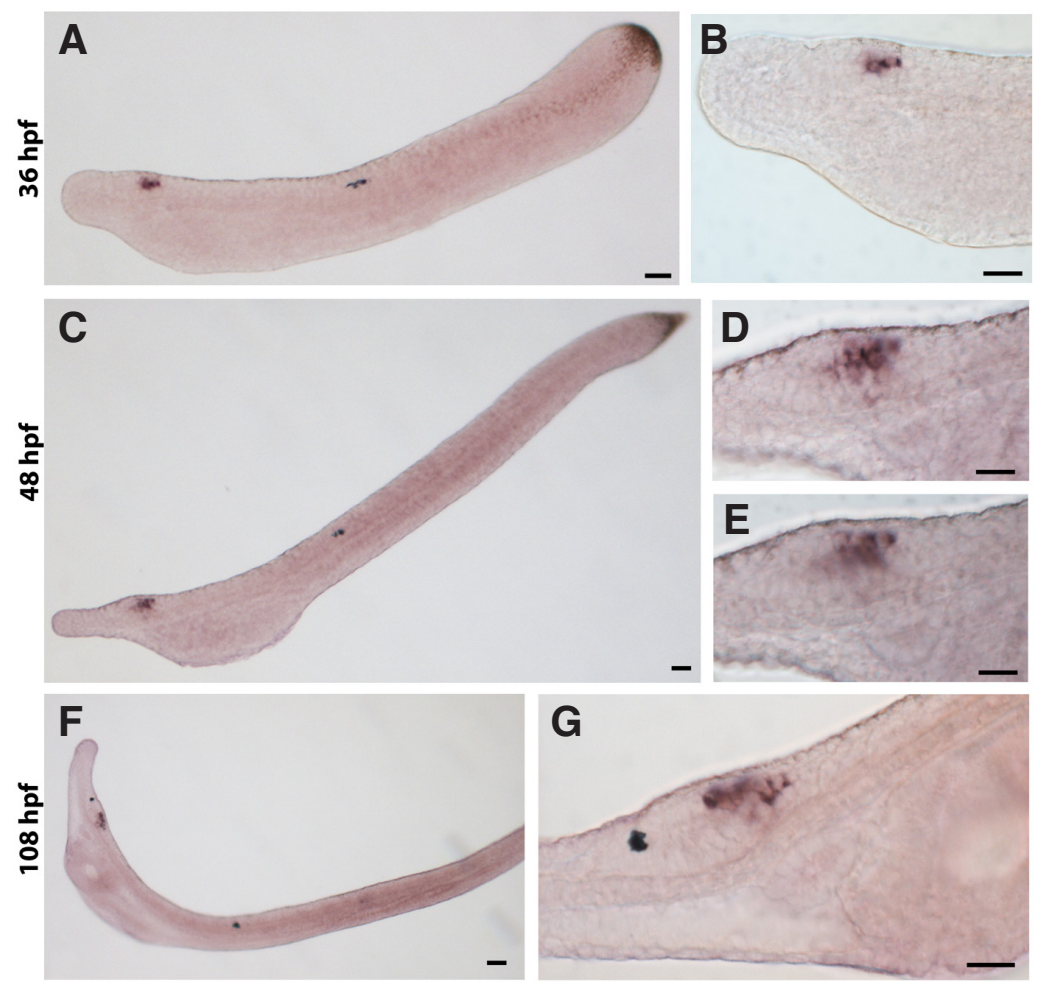

Fig. 1. Tyrosine hydroxylase (TH) mRNA expression in Branchiostoma lanceolatum larvae. (A) Side view of an early B. lanceolatum larva at 36 hours post fertilization (hpf). (B) Close-up of the anterior end of the specimen in (A), showing TH expression in the posterior cerebral vesicle. (C) Side view of a B. lanceolatum larva at $48 \mathrm{hpf}$. (D,E) Magnifications, at different focal planes, of the anterior end of the larva in (C). (F) TH expression in a B. lanceolatum larva at $108 \mathrm{hpf}$. (G) Higher magnification of the anterior end of the larva in (F). Coloration in the tail corresponds to tail pigment; anterior is to the left. Scale bars, $10 \mu \mathrm{m}$. 

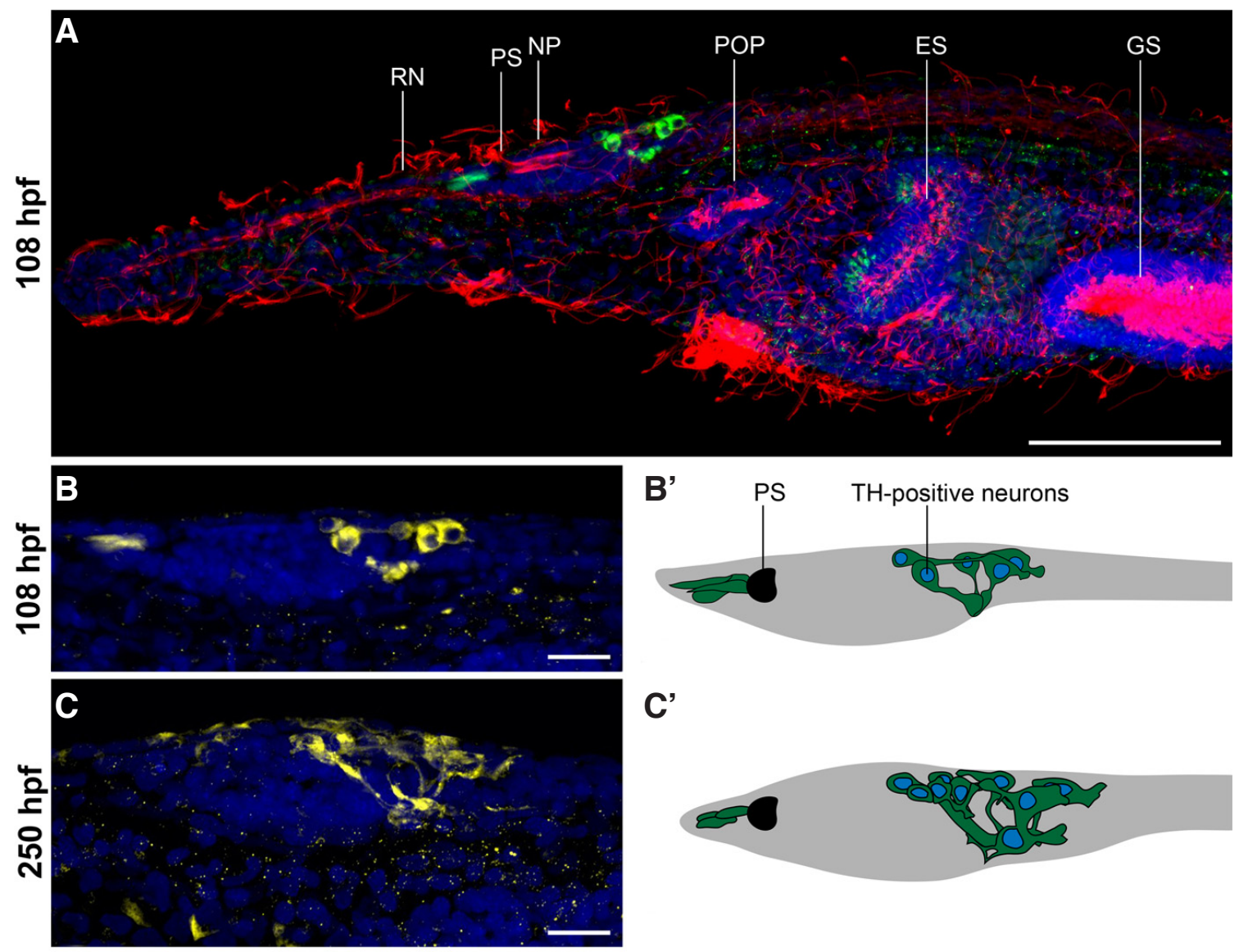

C'
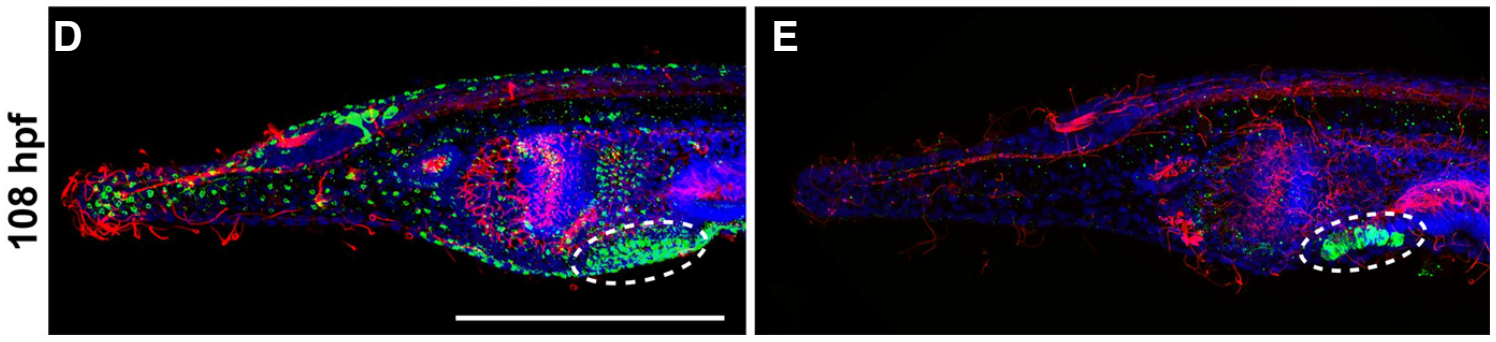

Fig. 2. Tyrosine hydroxylase (TH) and dopamine (DA) immunoreactivity in Branchiostoma lanceolatum larvae. Selected images from 15 specimens; these are maximum projections of confocal stacks taken at a step size of $0.8 \mu \mathrm{m}$. TH immunoreactivity is shown in green in (A,D), and in yellow in (B,C); DA immunoreactivity is shown in green in (E). Acetylated $\beta$-tubulin staining is shown in red in $(\mathbf{A}, \mathbf{D}, \mathbf{E})$ and nuclei (Hoechst labeling) in blue in (A-E). (A) Anterior region of a B. lanceolatum larva at $108 \mathrm{hpf}$ (hours post fertilization). (B) Close-up of the cerebral vesicle of the B. lanceolatum larva at 108 hpf in (A). (B') Schematic drawing of the TH+ cells of the B. lanceolatum larva shown in (B). (C) Close-up of the cerebral vesicle of a B. lanceolatum larva at 250 hpf. (C') Schematic drawing of the TH+ cells of the B. lanceolatum larva shown in (C). (D,E) Comparison between TH (D) and DA (E) immunoreactivity in the anterior region of $\mathrm{B}$. lanceolatum larvae at $108 \mathrm{hpf}$ on the right side. Signal overlap is highlighted with white dotted lines; anterior is to the left. Scale bars, $50 \mu \mathrm{m}$ in $(A, D, E)$ and $10 \mu \mathrm{m}$ in $(B, C)$. Abbreviations: ES, endostyle; GS, gill slit; NP, neuropore; POP, pre-oral pit; PS, pigment spot; $R N$, rostral nerve.

2). The results were consistent with our in situ hybridization data, but provide more cellular detail. Strong TH immunoreactivity can be detected in a cluster of six to eight neurons $(7.0 \pm 0.94, n=9)$ at $108 \mathrm{hpf}$, and eight to nine $(8.5 \pm 0.50, \mathrm{n}=6)$ at $250 \mathrm{hpf}$, and there are typically two to three additional faintly stained cells of which at least some clearly belong to the same cluster (Fig. 2 A-D). The neurons are located in the posterior cerebral vesicle, beginning just caudal to the point where the anterior, open portion of the central canal ends, i.e. at the level of the infundibular cells. Short, conspicuously thick $\mathrm{TH}+$ processes extend ventrally from the main part of the cell body towards the developing tegmental neuropile, where a mass of cellular processes and terminals is observed. In several instances, the nucleus of one $\mathrm{TH}+$ neuron was considerably more ventral than the others (Fig. 2 C,C'). The more usual situation is for the nucleus to remain close to the cell apex, while the rest of the cell body tapers, compressed by surrounding cells, until it reaches the top of the ventral neuropile. From there the axon arises, accompanied by irregular groups of terminals. However, based on TEM observations, it is clear that compression can also displace the nucleus ventrally, towards the base of the cell. A de- 
gree of variability in nuclear position is therefore to be expected.

We also observed TH immunoreactivity in a group of spindleshaped cells just rostral to the anterior pigment spot of the frontal eye (Fig. 2A-D). These correspond precisely with the pigment cells as seen in TEM, which would be actively synthesizing melanin at this stage, using L-DOPA as a precursor (Solano, 2014). Their distinctive narrow, conical shape is due to the way the rostral perinuclear part of each cell is compressed by the anterior tapering of the nerve cord. TH immunoreactivity was also detected in small clusters of cells in the endostyle and in the right oral papillae. Both structures are involved in mucus secretion, indicating an association between this function and catecholamines. Neither structure, from TEM analysis, contains neurons. THimmunoreactivity in peripheral structures is not corroborated by TH mRNA expression, which could be due either to lower sensitivity of our in situ hybridization protocol or non-specific antibody binding to other epitopes. Caution is therefore required in interpreting this result.

For comparison with TEM data (below), certain aspects of the
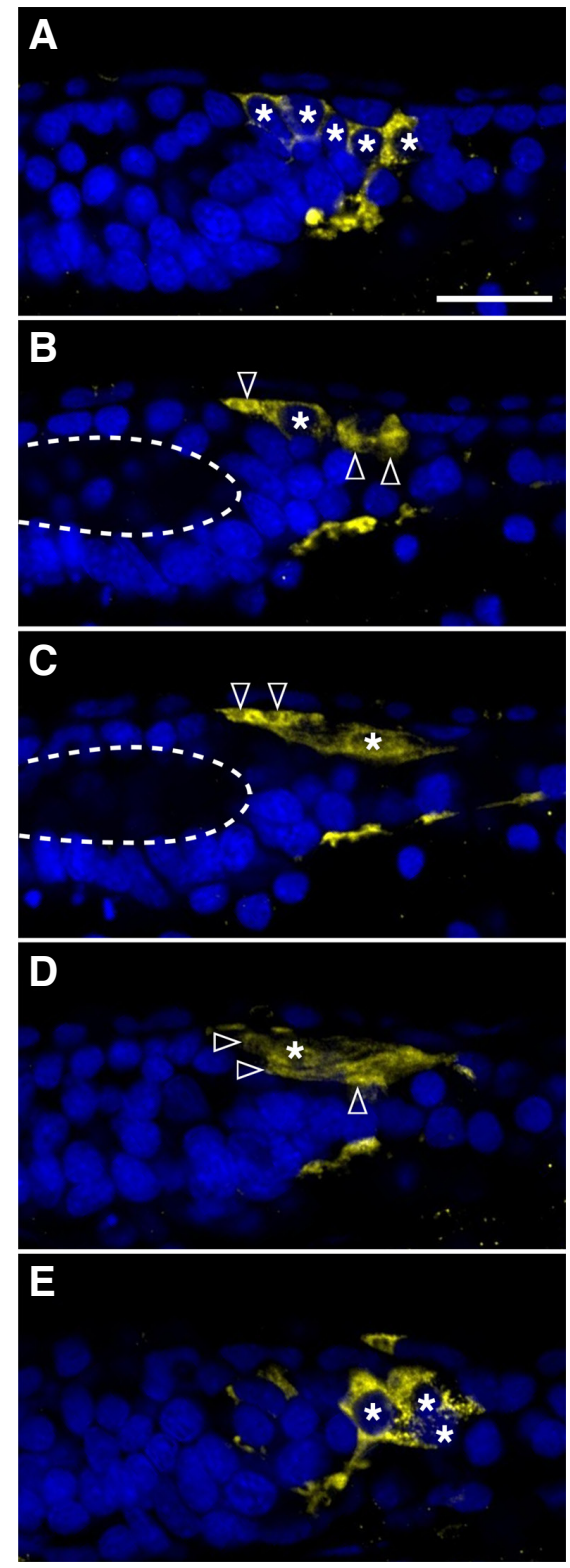

arrangement and morphology of the anterior-most $\mathrm{TH}+$ cells in the cerebral vesicle are especially noteworthy (see Fig. 3). The cell bodies are dorsolaterally positioned, on either side of the midline in an approximately symmetrical arrangement. There are five cells on each side in the specimen illustrated in Fig. 3, of which the two anterior-most on the left side (asterisks in Fig. 3C,D) would be categorized as faintly stained. Neurites project ventrally, and then expand to form groups of terminals (Fig. 3 A,E). There are also forward projections, four in this case (downward-pointing arrowheads in Fig. $3 \mathrm{C}$ indicate the two on the right side, horizontal arrowheads in Fig. 3D the two on the left), which we interpret as the apical portion of the anterior-most cells, and these converge near the caudal surface of the preinfundibular portion of the central canal in the same fashion as the apices of the cells we identify as their probable TEM counterparts (the PIN1s, see below). From the TEM data, there are no other cells in this location with exactly this combination of morphological features.

\section{Dopamine immunohistochemistry (B. lanceolatum)}

Using a specific antibody, DA immunoreactivity was observed only in the $\mathrm{TH}+$ cells located in the right oral papilla (Fig. $2 \mathrm{D}, \mathrm{E}$ ), while there was no detectable DA signal from cells in the cerebral vesicle. This could be for technical reasons, including inadequate fixation and photodegradation, both of which are known to be problematic. DAimmunoreactivity was, however, detectable in other non-neuronal larval tissues (Fig. 2E), and varying the method of fixation, including fixing in the dark, did not yield any CNS signal. As discussed below, the neurons in question may not be fully differentiated at the stages examined, and transiently use something other than DA (e.g. L-DOPA) as a transmitter.

\section{Cell identity and number, from serial TEM (B. floridae)}

Very little is available by way of TEM data for the amphioxus neurulae and larvae used here for localizing TH mRNA and TH protein. Young B. floridae larvae, up to about $150 \mathrm{hpf}$ (ca. 6 days), are comparatively poor subjects for TEM, because their neurons are not sufficiently differentiated to be clearly distinguishable either from one another or from non-neural cells, and the absence of fully differentiated nerve tracts complicates efforts to draw useful conclusions regarding synaptic patterns and vesicle types. The most useful and complete dataset available to date comes from a serial TEM analysis and reconstruction of the anterior nerve cord of a 300 hpf (i.e. 12-day) B. floridae larva (e.g. see Lacalli et al.,

Fig. 3. Morphological details of a Branchiostoma lanceolatum tyrosine hydroxylase (TH)+ neuronal cell cluster. Lateral view of the region around the anterior-most $\mathrm{TH}+$ cells at $250 \mathrm{hpf}$, anterior to the left, showing selected z-planes from a confocal stack, going from the right side of the head (A) to the left side $(\mathbf{E})$ and covering a distance of $14 \mu \mathrm{m}$. Cell nuclei are indicated (asterisks, five in total on each side) along with the inner surface of the open portion of the central canal region (dotted curve), which ends at the level of the infundibular cells; we see no indication of the anterior portion of the lamellar body in this region at this stage. Apical processes (arrowheads) can be seen extending towards this point from the left $(\mathbf{B}, \mathbf{C})$ and right (D) to converge near the medial plane (C). Matching the TEM data, we find two forward-projecting apices from the two anterior-most cells on the right (downward-pointing arrowheads), and two from the anterior-most cells on the left (horizontal arrowheads). Apices from more caudal cells (upward-pointing arrowheads) meet the central canal more caudally, ca. 10 to $12 \mu \mathrm{m}$ further back in this instance. Axonal projections are visible in (A,E), connecting to clusters of ventral terminals. Scale bar, $10 \mu \mathrm{m}$. 
1994; Wicht and Lacalli 2005), which is re-examined here in the light of our $\mathrm{TH}$ results.

Lacalli and Kelly (2003) identified four categories of neurons by TEM considered good candidates to contain biogenic amines, based on the general appearance of their fibers and complement of vesicles. In antero-posterior sequence (Fig. 4) these are: (1) type 1 preinfundibular projection neurons (PPN1s), whose apices are positioned well forward of the infundibular cell cluster, (2) type 1 parainfundibular neurons (PIN1s), whose apices lie just behind the infundibular cluster adjacent to the anterior-most floor plate cells, and $(3,4)$ type 1 and 3 tegmental neurons (TGNs), which form a mixed cluster in the ventral midline above the neuropile between about sections 700 and 900 . The TH data can be used to rule out cells in category (1) for being too rostral and those in categories
(3) and (4) for being too ventral in position and too caudal relative to other landmarks. This leaves the PIN1s, of which Lacalli and Kelly (2003) described and mapped two pairs (see their Fig. 2B). All four cells had slender or flattened (i.e. compressed) apices that project forward to emerge into the central canal just behind the point where the latter narrows from an open condition, characteristic of the anterior cerebral vesicle, to the more compressed canal seen along the remainder of the nerve cord. The lamellar body begins at this level as well, and its cells are the most dorsally positioned neurons in the cord of young larvae, lying just under the medial file of cells forming the roof plate.

The PIN1s are positioned below the lamellar cells, separated from them by one to two narrow files of other cells. None of the latter are differentiated neurons, so there are no other cells besides the
A

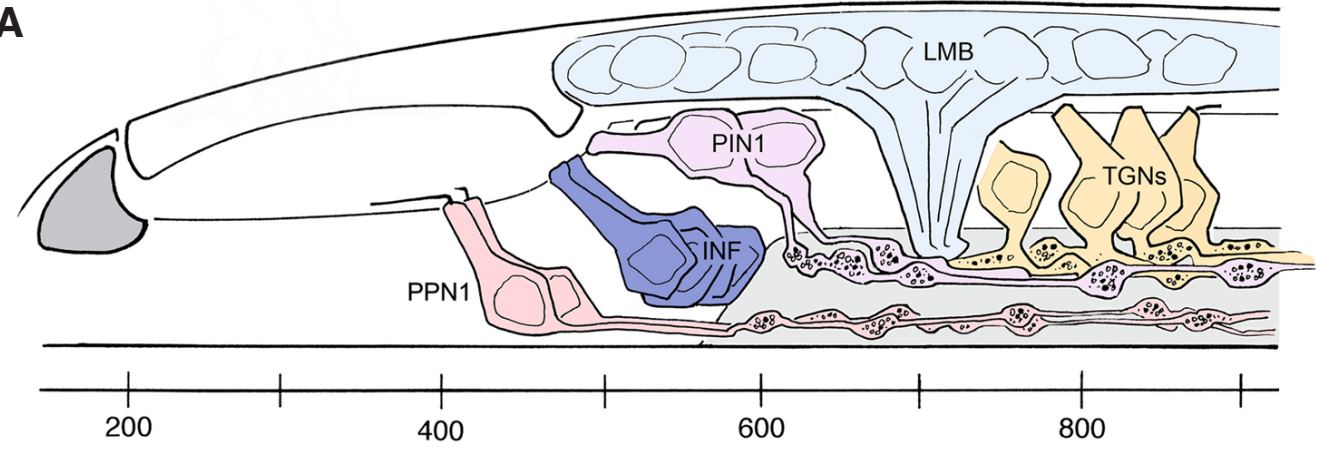

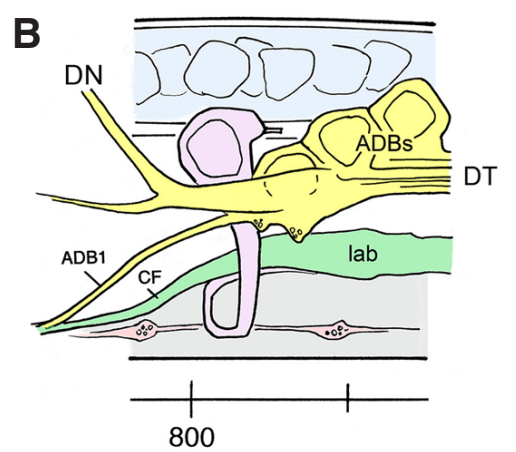

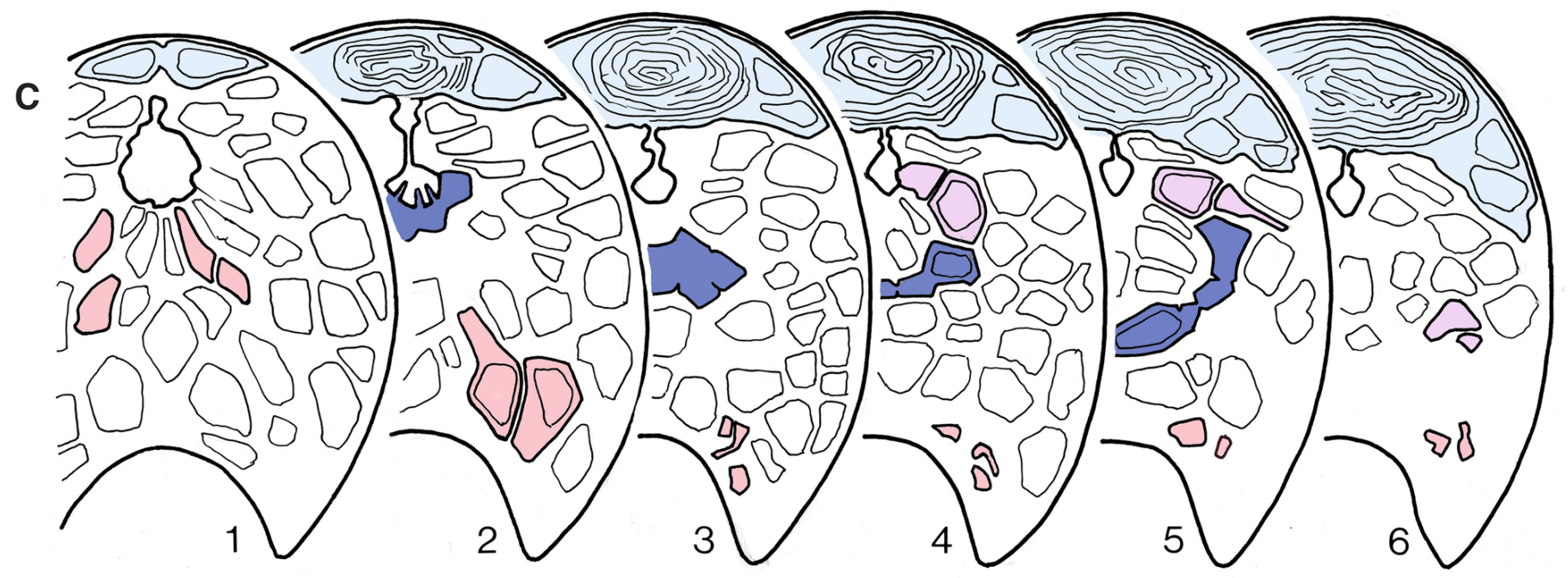

Fig. 4. Prospective aminergic neurons in Branchiostoma floridae larvae, from electron microscopical (TEM) data. (A) Side view, from serial TEM reconstructions, of the anterior nerve cord of a 300 hours post fertilization (hpf) (12-day) B. floridae larva, showing the relative positions of three classes of putative aminergic, type 1 neurons (preinfundibular projection neurons, PPNs; parainfundibular neurons, PINs; and tegmental neurons, TGNs, in pink, lavender, and beige respectively) in relation to the pigment spot of the frontal eye (grey), the lamellar body (LMB, light blue), and the infundibular cells (INF, dark blue). The tegmental neuropile is shown in light grey. This is a simplified, but accurate re-drawing of published data, taken largely from Lacalli and Kelly (2003), with section numbers along the bottom. The PIN1s correspond to cells expressing TH. (B) A more caudal example of a putative TH+ neuron (lavender), the left member of the fourth pair, showing its relationship to the anterior group of dorsal bipolar cells (ADBs, in yellow, of which $A D B 1$ is the anterior-most example on that side), the closely associated dorsal nerve and dorsal tract (DN and DT, respectively, also yellow), and the core fibers of the rostral nerve (CF), all of which converge on the left ascending bundle (lab, in green), containing forward-projecting dendrites of the large paired neurons (LPNS). This is where the rostral-most synaptic inputs to the LPNs occur, beginning at about section 800. (C) Selected sections, in 6 panels, showing more precisely how the PPN1s and PIN1s differ in terms of apex and cell position relative to the central canal and surrounding cells, shown as nuclear profiles. Colors as in (A). The series extends from section 410 (panel 1) to 660 (panel 6), with about a 50 section (3.4 um) interval between panels. Abbreviations: ADB, anterior dorsal bipolar neuron; CF, rostral core fiber; DT, dorsal tract; DN, dorsal nerve; INF, infundibular cells; lab, left ascending bundle; LMB, lamellar body; PIN, parainfundibular neuron; PPN, preinfundibular projection neuron; TGN, tegmental neuron. 
PIN1s in this region to be confused with those in the TH preparations. The remaining type 1 neurons, which from our results do not contain TH, also differ from PIN1s in having terminals containing a somewhat different mixture of clear and dense-cored vesicles and, consistent with a role in paracrine transmission, have few, if any, synapses. The predominant type of vesicle in PIN1 axons and terminals are of intermediate size (45 to $60 \mathrm{~nm}$ ) and somewhat irregular profile. They have faint central condensations of moderate density and form crowded, somewhat irregular arrays at presynaptic sites (see Fig. 3 B,C,E in Lacalli and Kelly 2003). Where clear vesicles are present, their small size and comparative rarity suggests in most cases that they are the same vesicle type cut off axis, so as to miss the central condensation. We conclude that most PIN1 synapses employ one vesicle type, though we have also found a few synapses, chiefly to preinfundibular fibers (e.g. of PPN1s), where small clear vesicles appear to predominate. Larger, more densely stained dense-cored vesicles also occur in small numbers in PIN1s, near the Golgi, and in fibers, but seldom at or near synapses.

It is somewhat ambiguous whether PIN1s should be considered dorsal neurons or ventral ones. The main part of the cell body is dorsally positioned (Fig. 4A), matching the $\mathrm{TH}$ preparations, but this is because the cells are pushed upwards by the mass of neuronal cell bodies displaced caudally from the preinfundibular region (see profiles 4 and 5 in Fig. 4C). PIN1 apices, in contrast, project into the ventral part of the central canal, and are either adjacent to, or one cell apex removed from the apices of the anterior-most floor plate cells (see Fig. 4, in Lacalli and Kelly 2003). Such close proximity to both the most dorsal and most ventral cells in the cord is possible only because the central canal is very small at this point, and most of its inner surface is taken up by the expanded apices of the lamellar cells. In searching for other $\mathrm{TH}+$ neurons, proximity to the lamellar body (i.e. dorsal positioning) has proven the relevant criterion, allowing us to identify four additional neurons that are potentially of similar type. These are arranged roughly in pairs as shown in Fig. 5A, although one cell (blue in the figure) is sufficiently different that we have doubts that it belongs to the same category. All four cells have apices significantly smaller than those of the more rostral PIN1s: 0.7 to $0.95 \mu \mathrm{m}$ and approximately circular for the former, compared with 3.4 to $4.5 \mu \mathrm{m}$ and elongate for the latter. Apex length in amphioxus neurons can be used to estimate the relative times of neuron differentiation, as it depends on the timing of the terminal cell division relative to the elongation phase of the late-stage neurula (Lacalli 2000). On this basis, all four of the more caudal members of the PIN1-like class are considerably younger than the anterior PIN1s, as are the various tegmental neurons. These differences are reflected in the input patterns as described below, which place the anterior-most PIN1s as both the earliest of this class of the $\mathrm{TH}+$ neurons to differentiate and the founders of the basic circuits to which other members of the class later contribute.

Fiber tracing and synaptic patterns, from serial TEM(B. floridae)

Because their axons are small and frequently compressed by surrounding fibers, few of the individual TH+ fibers (i.e. PIN1 and PIN1-like) could be traced with confidence much beyond the region shown in Fig. 5A. There are numerous inputs to all eight cells within this region, though with differences that correlate with the relative time of differentiation. Outputs are predominantly from the anterior two pairs of $\mathrm{TH}+$ neurons, so we assume the main output from more caudal pairs lies further back in the section series. Axons belonging to five of the eight cells (one was lost, two cross to the other side) converge to form a medial bundle just beneath the floor plate in the region of section 800 . The bundle then shifts gradually to the right and joins the upper paraxial bundle (upb) on the right side. Having a medial point of mutual contact also occurs with crossing fibers of other cell types in our specimen, including the large paired neurons (LPNs) and commissural neurons (CNs, see Figs. 3A, 7A, 10A, in Lacalli and Kelly 2003), suggesting this may be a way of organizing early fiber projections. During their transit down the right side of the cord, the $\mathrm{TH}+$ fibers become increasingly difficult to trace individually. They continue as a group, but we do not know how far they travel or their eventual targets, except for LPN and $\mathrm{CN}$ axons, which receive synaptic input from identifiable $\mathrm{TH}+$ fibers beginning at about section 1250 .

Despite the problems encountered in tracing, a consistent pattern of inputs to $\mathrm{TH}+$ neurons can be recognized, and the transit of their axons together in the upb in five cases out of eight suggests that these cells at least should be classed together as belonging to the same neuronal subtype. Inputs include the rostral core fibers (CFs) and anterior dorsal bipolar cells (ADBs, equivalent to the tectal cells, T, in Lacalli and Kelly 2003), which are also inputs to the escape response, for which the LPN3s, located in the primary motor center (PMC), appear to be central. A difference is that, while sensory and ADB input to the LPNs are massively redundant (see Fig. 5, in Lacalli and Kelly 2003), TH+ neurons typically make fewer contacts, and individual synapses are comparatively small.

For the four anterior $\mathrm{TH}+$ neurons, outputs are to LPN dendrites and axons, to $\mathrm{CN}$ axons in a few cases, to a type 3 ascending fiber (AX3), and to an assortment of tegmental neurons (TGNs, mapped in Fig. 2, in Lacalli and Kelly 2003). Among the latter is a category referred to as second-order neurons with descending fibers (SDFs), which are major targets of the first four $\mathrm{TH}+$ neurons. The SDFs can be distinguished from other TGNs by their descending fibers, predominantly clear vesicles, and well-defined synapses. Most other TGNs are more variable in morphology, with multiple branched neurites of mainly local extent, and irregular large terminals containing mixed populations of vesicles. Where junctions with TGNs occur, the polarity is often ambiguous, which makes it difficult to recognize subclasses within the TGNs based on morphology and input/output patterns. The SDFs, as a class, can be defined by always being post-synaptic to $\mathrm{TH}+$ neurons via well-defined synapses, often to the base of the cell (see Fig. 3B, in Lacalli and Kelly 2003, the central small arrow in Fig. 3D shows a TH+ synapse to a basal dendrite from an adjacent SDF). The most active SDF, in turn, synapses with motoneurons (MNs), CNs, and an extensively connected multipolar neuron (MP, see Fig. 9D, in Lacalli and Kelly 2003, the large ascending fiber in this figure is mistakenly identified and is, instead, a continuation of the large SDF fiber shown here in Fig. 5A). We are uncertain as to the targets of less active SDFs.

$\mathrm{TH}+$ neurons also form synapses with each other, where their fibers meet near the midline, and with fibers originating in the preinfundibular region, including some belonging to PPN1s. In a few cases, we also identified synapses to what appeared to be rostral sensory fibers that synapse in turn with MNs, and in one case a direct synapse between the anterior-most $\mathrm{TH}+$ neuron on the left and a MN on the right, as shown in Fig. 5A. Contacts with 
type 2 PPNs (PPN2s) occur at several points, but are not obviously synaptic except for two cases: on each side there is a specialized junction, possibly synaptic, between the axon of an anterior $\mathrm{TH}+$ neuron and one of the two PPN2 fibers. These are both ipsilateral contacts, and both occur on a branch from the principle PPN2 fiber, which develops in part as a terminal and ends, on the left side, in a post-synaptic bulb-like specialization that is enclosed by the $\mathrm{TH}+$ axon. This occurs at section 685, as indicated in Fig. 5A. The polarity of the comparable junction on the right, at section 760 and also indicated in Fig. 5A, is less easily interpreted. The PPN2s are involved in the dorsal compartment (i.e. the slow-twitch) motor circuit, so this implies an early involvement of the $\mathrm{TH}+$ neurons in this function.

Assuming that the $\mathrm{TH}+$ neurons of amphioxus larvae use DA or a related catecholamine neurotransmitter or neuromodulator, the TH system likely functions as a parallel pathway for controlling the escape response and, perhaps, other locomotory functions, with the added feature of recruiting an assortment of additional
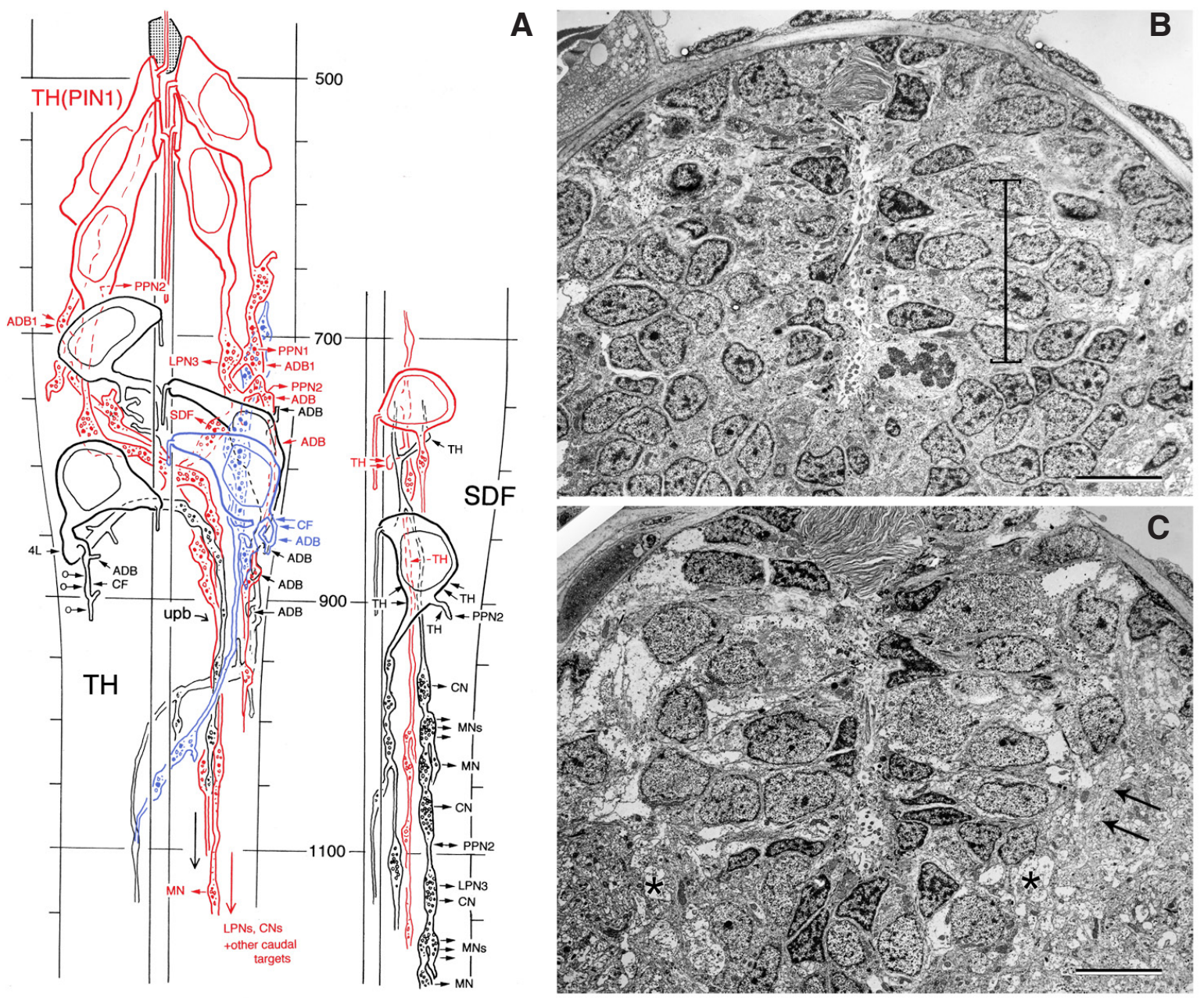

Fig. 5. Prospective tyrosine hydroxylase (TH)+ neurons in a Branchiostoma floridae larva, and their juvenile counterparts, from electron microscopical (TEM) data. (A) Dorsal view of the anterior nerve cord of the 300 hours post fertilization (hpf) (12-day) B. floridae larva reconstructed from the level of the infundibular cell apices (shaded) to about section 1200, showing putative TH+ neurons, and, to the right, two of the second-order neurons with descending fibers (SDFs) that receive $\mathrm{TH}+$ input. $\mathrm{TH}+$ neurons in red are the type 1 parainfundibular neurons (PIN1s) described previously by Lacalli and Kelly (2003) (see their Fig. 2A for a more complete map of inputs and outputs). Cells newly described in this account are in black and blue, the latter color marks the one cell least like the others, which may therefore be of a different type (see text for details). Arrows show selected synaptic contacts. Among the key inputs to TH+ neurons are those from the anterior group of dorsal bipolar cells (ADBs), including the anterior-most of these (ADB 1), and in one case from the frontal eye via cell $4 L$. Key TH+ targets include the SDFs and the large paired neurons (LPNs). All inputs shown to the former are from the anterior two pairs of $\mathrm{TH}+$ neurons, but the terminals responsible are largely obscured in this view by overlying cell bodies. Arrows topped with open circles indicate synapses from unspecified dorsal tract sensory fibers. (B,C) Two sections through the juvenile nerve cord, separated by about $10 \mu \mathrm{m}$. (B) shows a dorsal stack of neurons (vertical bar) located just behind the front of the lamellar body, matching the anterior portion of the Population 1 dopaminergic center reported by Moret et al. (2004). Bundles of fibers similar to those described by Moret et al. (2004) descend ventrally on either side, arrows in (C) for the left tract, to join a pair of fiber tracts, marked by asterisks. Note that the compressed part of the central canal is largely open, as both sections lie forward of the point where translumenal neurons become major components of the dorsal nerve cord. Scale bars, 5 um. Abbreviations: $4 L$, frontal eye neuron; $A D B$, anterior dorsal bipolar neuron; CF, rostral core fiber; CN, commissural neuron; LPN, large paired neuron; MN, motoneuron; PIN, parainfundibular neuron; PPN, preinfundibular projection neuron; SDF, second-order neuron with descending fibers; TH, tyrosine hydroxylase-containing neuron; upb, upper paraxial bundle. 
interneurons to these pathways. Interestingly, the pathway as a whole appears to be biased to the right, with the majority of both $\mathrm{TH}+$ and SDF fibers projecting to the upb on that side. The location of the upb tends to reinforce our conclusion that there is no direct output to $\mathrm{MNs}$ from $\mathrm{TH}+$ neurons aside from the one example mentioned above. This is because, as a group, the $\mathrm{TH}+$ fibers remain confined to the region medial to the upb, adjacent to the notochord, as they travel caudally. From there, they would have no direct access to MN dendrites, which are generally short and restricted to more ventrolateral parts of the neuropile.

\section{Serial TEM details for individual neurons (B. floridae)}

The cell bodies of the first $\mathrm{TH}+$ pair taper beyond the level of the nucleus and enter the neuropile quite far forward. They then produce a complex set of fibers and terminals. Those arising from the cell on the right are especially well developed, with multiple branches and numerous terminals, and do not cross the midline. Instead, they penetrate quite deeply into the ventrolateral neuropile, close to the motor tracts, and may terminate there, as we were unable to discover caudally projecting fibers beyond section 860. The principal fiber from the anterior-most of the $\mathrm{TH}+$ neurons on the left side has at most a few dendrites, no major branches, and comparatively few terminals. It traverses the neuropile to the ventral midline, just beneath the floor plate, and joins the medial bundle of other DA fibers that eventually, in turn, joins the right upb.

Inputs to the anterior-most $\mathrm{TH}+$ neurons are typically received on small spines or en passant. Fibers from both the right and left members of the pair contact and receive synaptic input from the forward-projecting fiber of the anterior-most of the ipsilateral ADBs (ADB1 in Fig. 4B). The anterior-most ADBs are the only members of that class whose rostral neurites project ventrally and exit the cord via the rostral nerves. Fibers from all other ADBs exit via dorsal nerves. The difference is probably due to the anterior-most ADBs developing first, at a time when the dorsal tracts are not yet established, leaving the rostral pathway as the only means of exit. We did not find direct inputs from the rostral core fibers to the anterior-most $\mathrm{TH}+$ neurons, though they synapse to some other members of the class.

Cells of the second $\mathrm{TH}+$ pair have better defined dendritic arbors. These are not large, but project dorsally to receive synapses, along with adjacent LPN3 dendrites, from the rostral fibers, dorsal tract fibers, and ADBs. Outputs include synapses to LPN3 dendrites and various TGNs, in the latter case both to fibers in passing and to the bases of the cell bodies. Axons from both meet near the midline and travel, with other $\mathrm{TH}+$ fibers, to the right upb. As above, the axon from the left cell crosses, while the one from the right does not. Both continue in this tract, but the one from the left has the most terminals and forms a series of contacts, including synapses with the LPN1, 2, and 3 axons in the region where they cross.

Neither of the cells of the third pair have projections like those of the other cells, but for two different reasons. The cell on the left (apex at section 680, Fig. 5A) is unusual in squeezing between more medial cells rather than projecting laterally, so its basal fiber emerges near the center of the neuropile. Several long dendrites then branch from the fiber before we lose it among the other $\mathrm{TH}+$ fibers where they meet medially. Because of the fiber's mid-ventral location, there is no opportunity for its branches to encounter the CFs, ADBs or dorsal tract fibers that provide input to other $\mathrm{TH}+$ neurons. The principle fiber from the cell on the right projects to the dorsal tract, which abuts its base and travels for some distance with the tract receiving repeated synapses from the ADBs. The fiber is then diverted ventrally into the lateral neuropile and traverses the midline below the level of the upb, thereby missing any contact with other $\mathrm{TH}+$ fibers. On the left side of the cord, the fiber continues caudally near the top of the notochord, in a position much like that taken by other $\mathrm{TH}+$ fibers on the right. This cell has been previously illustrated (Fig. 9B, in Lacalli and Kelly 2003) and erroneously categorized as an anterior commissural neuron. If both members of this pair are $\mathrm{TH}+$ neurons, their morphology suggests that later-developing members of the class face a different situation in terms of the surrounding fibers and potential targets they encounter, and vary morphologically for that reason. $\mathrm{TH}+$ neurons appear therefore to be opportunistic in the contacts they make, which may be a means of supplying new targets and pathways as these emerge during development.

Cells of the fourth $\mathrm{TH}+$ pair abut the dorsal tracts on their respective sides, so each has direct access via dendritic arbors to both this tract and the bundle of rostral core fibers, located just below, and both have well-developed axons. The left member of the pair has an especially large dendritic arbor and receives inputs typical of other $\mathrm{TH}+$ neurons, but has few outputs in the region examined. Its axon was lost among the other fibers of the upb by the end of somite 1 , but the paucity of terminals up to this point suggests it has significant output more caudally. The right member (blue in Fig. 5A) differs in several respects from all other members of the $\mathrm{TH}+$ class. It has an ascending fiber that projects forward through the center of the lateral neuropile on the right, dips to the ventral region in places, and expands to produce a series of very large terminals. Targets include a number of fibers presynaptic to MNs. This cell is also unusual in having terminals containing many more large dense-core vesicles $(60$ to $70 \mathrm{~nm}$ in diameter and very dense) than are found in other $\mathrm{TH}+$ terminals, and far fewer of the numerous small vesicles have visible contents. Despite its similarity in other respects to other $\mathrm{TH}+$ neurons and frequent contacts with their fibers, this one cell is almost certainly a different, but perhaps related cell type.

\section{Onset of muscle-based undulatory swimming(B. lanceolatum)}

It has previously been shown that early $B$. floridae larvae initially exhibit only unilateral bends and progressively obtain the ability to swim with an undulatory motion during subsequent development (Stokes 1997; Lacalli and Kelly 2003). Observing the onset of swimming in B. lanceolatum larvae in slow motion (Movie 1), we found that, in contrast to reports on $B$. floridae, the initial motions of $B$. lanceolatum larvae typically consist of a bend that is followed by a counter-bend to the contra-lateral side. The first bend uses more anterior myotomes than the counter-bend. As the larvae elongate, they show longer series of contralateral bends that gradually involve more myotomes. The contraction of these myotomes in an anteroposterior progression eventually results in an undulatory swimming movement.

\section{Discussion}

\section{The tyrosine hydroxylase system: organization and function}

Our molecular and TEM data, in combination, define the early population of amphioxus $\mathrm{TH}+$ neurons in an unambiguous way, as consisting of a small number of dorsally positioned neurons 
in a region that extends from the front of the lamellar body to about the midpoint of the tegmental neuropile. We could typically identify between eight and twelve cells in 4.5-day and 10.5-day $B$. lanceolatum larvae, and eight cells (one questionable) by TEM in a 12-day $B$. floridae specimen.

Based on TEM data, synaptic input to the $\mathrm{TH}+$ neurons is from fibers in the rostral and dorsal nerves, from the ADBs, and from the frontal eye (FE) (Fig. 6). The same cells and fibers are presynaptic to the LPNs that serve as central components of the main pathway for activating the escape response. The $\mathrm{TH}+$ system appears therefore to be a parallel pathway that serves to recruit a number of additional, second order interneurons to the escape response, including TGNs and SDFs. There appears also to be a sequence in the development of $\mathrm{TH}+$ neurons, with the anterior-most pair of cells developing first and receiving their main input from the anterior-most of the ADBs, whereas later-developing, more caudal

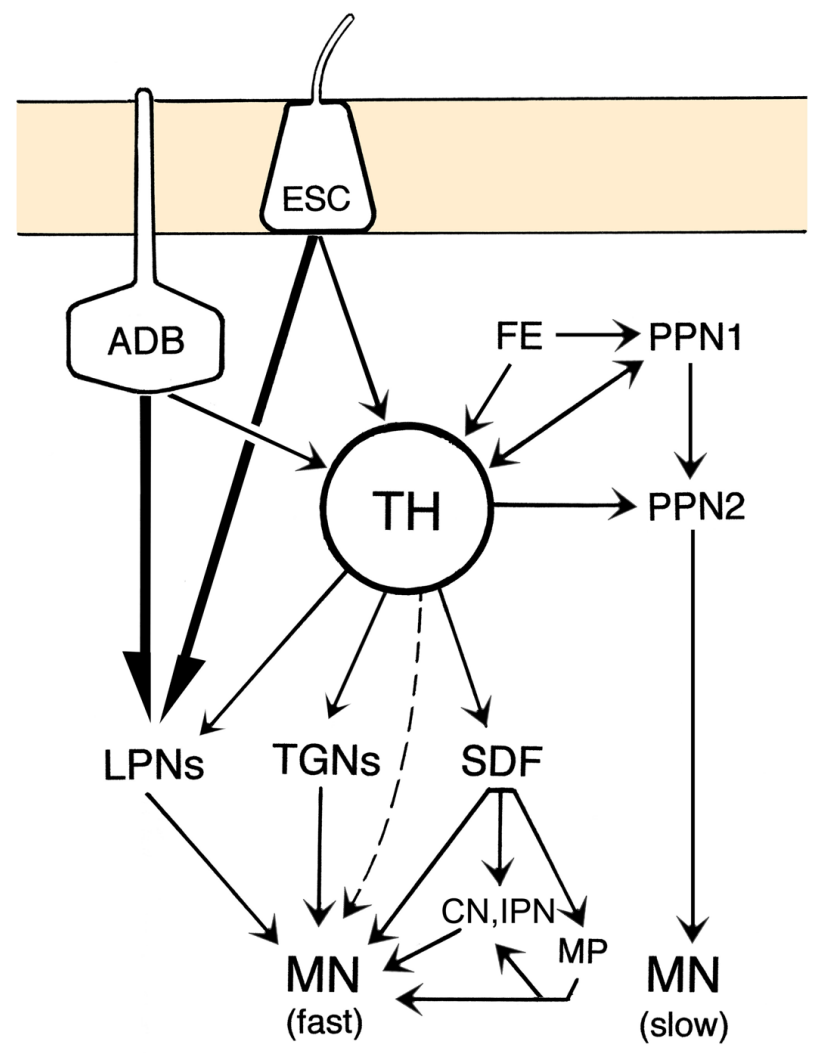

Fig. 6. Synaptic inputs and outputs to the amphioxus tyrosine hydroxylase (TH)+ system. A summary of our observations on $\mathrm{TH}+$ neurons in developing amphioxus larvae. For the TH+ neurons, there are differences between cells depending on their age and location, so not all make the contacts shown, e.g. the frontal eye (FE) input via cell $4 \mathrm{~L}$ is to one $\mathrm{TH}+$ neuron. The plural " $\mathrm{s}$ " is used if that category has multiple cell subtypes. Thicker lines indicate redundant input pathways with large numbers of synapses, and the dotted line is a direct TH-to-MN synapse, of which we have so far found only one example. The last is likely a relict of early development and possibly of limited functional importance to larval behavior. Abbreviations: $A D B$, anterior dorsal bipolar neuron; $C N$, commissural neuron; ESC, epithelial sensory cell; FE, frontal eye; IPN, ipsilateral projection neuron; $L P N$, large paired neuron; $M N$, motoneuron; MP, multipolar neuron; PPN, preinfundibular projection neuron; SDF, secondorder neuron with descending fibers; TGN, tegmental neuron; TH, tyrosine hydroxylase-containing neurons. members of the $\mathrm{TH}+$ class have more complex dendritic arbors and receive a more varied input from fibers in the dorsal tracts, as well as having caudal projections with fewer outputs in the region examined. The synaptic targets of the $\mathrm{TH}+$ system include fibers with major inputs to the MNs on the right side, and in general most of the projections arising from both the $\mathrm{TH}+$ neurons and their targets are biased to the right.

We are currently unable to identify the transmitter used by our $\mathrm{TH}+$ neurons with certainty. TH catalyzes the formation of L-DOPA, which can then act as a neurotransmitter in its own right (Misu and Goshima 2006; Hiroshima et al., 2014), or is transformed into other catecholamines, e.g. dopamine, noradrenaline or adrenaline (Daubner etal., 2011). DA-containing neurons have previously been reported in the anterior nerve cord of adult amphioxus (Moret et al., 2004), but we were unable to detect DA itself in the larval cerebral vesicle. Conversion into other catecholamine neurotransmitters is unlikely, since HPLC analyses of the monoamine content of adult amphioxus revealed high levels of L-DOPA and DA, but no noradrenaline or adrenaline (Moret et al., 2004). Larval $\mathrm{TH}+$ neurons could nevertheless be dopaminergic, but not fully differentiated in the stages we have examined. L-DOPA, a DA precursor, is the most likely alternative as transmitter, and could be used transiently in cells that only later adopt a mature DAergic phenotype. L-DOPA and DA can act as both excitatory and inhibitory neurotransmitters, as neuromodulators that tune the excitability of one or many target cells, and as neurohormones (Ben-Jonathan and Hnasko 2001; Callier et al., 2003; Misu and Goshima, 2006). L-DOPA interacts with most DA receptors, so neural circuits involving either transmitter would likely function in an essentially equivalent way. Amphioxus possesses vertebrate- and invertebrate-like D1-like dopamine receptors (Candiani et al., 2005; Burman and Evans 2010) and at least one D2-like receptor (Bayliss and Evans 2013). The former typically transmit excitatory signals while the latter are better known for modulatory or inhibitory effects. To date, expression in the cerebral vesicle has only been shown for D1-like receptors (Candiani et al., 2005), suggesting that our $\mathrm{TH}+$ neurons would most likely be excitatory. In relation to L-DOPA, it is worth noting its role in retinal patterning through the release of pigmentepithelium-derived factor (Lopez et al., 2008). A similar role for our TH+ neurons in amphioxus is a possibility, in which case the acquisition of a full DAergic phenotype might be delayed if competitive binding by DA blocked this mechanism.

Across the animal kingdom, DA is crucially involved in motor control (Barron et al., 2010), which could be relevant to the role $\mathrm{TH}+$ neurons play in amphioxus larvae. Our TEM observations, based on one specimen, show asymmetries in $\mathrm{TH}+$ projections, and the initial stages of muscular swimming in amphioxus also show marked asymmetric features: the first muscular twitches of $B$. floridae have been reported as repeated and to one side (Stokes 1997; Lacalli and Kelly 2003), and in B. lanceolatumbegin anteriorly on one side followed by a counter-twitch of more caudal myotomes on the opposite side (Movie 1). In both amphioxus species, a more rapid, rhythmic pattern of alternating contractions then develops progressively (Movie 1) (Stokes 1997; Lacalli and Kelly 2003). From a reassessment of the neurochemical data (Candiani et al., 2012; Lacalli and Candiani 2017), it appears that all the ventral neurons in the vicinity of the LPNs are excitatory except for a small, more anterior group of GABA-containing CNs. The LPNs and the $\mathrm{TH}+$ system, therefore, appear to be providing multiple 
sources of excitatory and/or modulatory input to the anterior MNs. An asymmetric muscular response would require either excitatory inputs that develop asymmetrically or an asymmetric input that is inhibitory. An important point here is that the SDFs can be ruled out as containing the inhibitory neurotransmitter GABA, so their effect in amphioxus should be an excitatory one, also biased to the right. There are, however, other early sources of excitatory input biased to the left, notably the contralateral axon of the right LPN3, which targets the left MNs via especially long dendrites (see Fig. 7 F,G, in Lacalli and Kelly 2003). The latter feature is an indication that the connection is made very early, with the dendrites being stretched passively as the intervening neuropile thickens. On the right side, in contrast, the contralateral axon of the left LPN3 forms comparatively few synapses, and most LPN input to MNs comes instead from the left LPN2. This, along with a variety of other minor asymmetries means that, from a circuitry standpoint, the situation is very complex and depends on asymmetries among an assortment of excitatory inputs. A further complication is that we also do not know which category of motor fibers, fast twitch or slow twitch, is first to function. Based on the data currently available, therefore, we are unable to draw any firm conclusions regarding the role asymmetrical $\mathrm{TH}+$ projections play in the first muscular responses. Circuit asymmetry is now known to also be a feature of the escape pathway in ascidian tadpole larvae (Ryan et al., 2016), and there is some justification for comparing the startle response in the latter with that in vertebrates controlled by Mauthner neurons (Ryan et al., 2017). We do not, however, have any evidence relating the larval locomotory center in amphioxus to either of these two systems, and the former (the PMC) is in any case positioned too far forward for any of its cells to be direct homologs of Mauthner neurons, which are located in the hindbrain.

By 3 to 4 days of development, amphioxus larvae are capable of a much greater range of swimming behaviors, from brief twitches to either short or sustained bouts of swimming of varied intensity. Explaining these requires either a multiplicity of circuits or, more likely, a core circuit whose output can be modulated by one or more accessory circuits. The $\mathrm{TH}+$ system could be one such accessory circuit, whose role may be to sustain the swimming response beyond the time when the initiating stimulus has ceased. While we have no direct evidence to support this, it is consistent with the observation that some of the largest terminals belonging to descending axons that target MNs are downstream in the $\mathrm{TH}+$ pathway, so synaptic activity in these fibers could conceivably continue for some considerable time. In addition, because the anterior-most $\mathrm{TH}+$ neurons develop so early (their apices are the longest of any of the anterior neurons) and have so many different synaptic targets, we speculate that they may play a role throughout early development, providing input to multiple pathways as each is established. This implies that the functions of early- and later-developing $\mathrm{TH}+$ neurons could differ, depending on which pathways happen to be developing at any given time. Furthermore, the complexity of DA signaling in vertebrates, which relies on multiple receptor types and downstream effectors (Ben-Jonathan and Hnasko 2001; Callier et al., 2003), suggests that amphioxus $\mathrm{TH}+$ neurons might have additional functions beyond the modulation of larval locomotion. For example, because the amphioxus D1/ $\beta$-adrenergic receptor is expressed in the vicinity of the pre-oral pit, a putative pituitary homolog (Candiani et al., 2005), there could be a neurohormonal release of catecholamines, such as DA from amphioxus $\mathrm{TH}+$ neu- rons, similar to that occurring in vertebrate hypothalamo-pituitary DA systems (Ben-Jonathan and Hnasko 2001).

\section{Comparative and evolutionary considerations}

The results of Moret et al. (2004) show a large anterior cluster of DA neurons (their Population 1), whose rostral limit corresponds to the location of our early-stage cluster of $\mathrm{TH}+$ neurons. We find similar cells in this same location in TEMs of the juvenile stage (Fig. 5B), along with short, ventrally directed nerve tracts (Fig. 5C) resembling those described by Moret et al. (2004) as containing DA. This convinces us that we are almost certainly dealing with the same group of neurons in our amphioxus specimens, regardless of species or age, though the presence of DA itself in the larval CNS remains to be demonstrated. By the adult stage, Population 1 occupies a dorsal domain extending from the anterior end of the lamellar body to the beginning of somite 2, with its cells concentrated towards the rostral end of this domain. For the purposes of this section, comparing our amphioxus results and those of Moret et al. (2004) with the situation in other chordates, we will refer to our $\mathrm{TH}+$ cells as putative/pre-DA (pDA) neurons.

DA neurons in vertebrates occur in a series of nuclei in the diencephalon and rostral midbrain (O'Connell and Hofmann 2011; Yamamoto and Vernier 2011), but the absence of midbrain DA centers in lampreys and teleosts (Ekström et al., 1992; Abalo et al., 2005) has been interpreted as evidence that they evolved later than those in the diencephalon (Yamamoto and Vernier 2011). If so, the region occupied by Population 1 DA neurons in amphioxus should be homologous to all or part of the diencephalon. From the rostral part of this region, pDA fibers project to the PMC, a probable homolog of the vertebrate mesencephalic locomotor region (MLR). Accordingly, the pattern in young amphioxus larvae seems to match that in lamprey, where diencephalic DA neurons project to the MLR (Sirota et al., 2000; Ryczko et al., 2013), and there are comparable projections in other vertebrates from the A11 cell group, a DA nucleus located in the caudal diencephalon. The similarity of the amphioxus lamellar body to the pineal supports this interpretation, implying that the whole of its extent, from the level of the infundibular cells to nearly the end of somite 1 (i.e. the posterior cerebral vesicle in the terminology of Lacalli et al., 1994), is homologous to the vertebrate diencephalon. However, on morphological grounds the issue is more complex than this correlation implies (Lacalli 2017), and there is compelling new molecular evidence (Albuixech-Crispo et al., 2017) that the domain in question actually combines the amphioxus counterparts of the thalamus, pretectum, and midbrain. The distinction between this domain (the diencephalo-mesencephalon primordium, or Di-Mes in the authors' terminology, which we will refer to here as the dien-mesencephalon) and the rest of the forebrain may thus be evolutionarily more important than the conventional distinction between forebrain and midbrain.

Comparing the distribution of DA neurons in amphioxus and vertebrates in more detail, there is first a difference in dorsoventral positioning. Diencephalic nuclei can be quite dorsal in vertebrates (e.g. the pretectal nucleus, A11, and A13), while mesencephalic nuclei (A9 and 10) are considerably more ventral. In amphioxus, in contrast, the anterior-most of our pDA neurons (the PIN1s) are difficult to assess in this context, as they are equally close to both the floor plate and roof plate, while more caudal pDAs and all of Population 1 are clearly dorsal relative to other neurons in 
the cord. This is not so much a problem, as a consequence of the difference in scale between amphioxus and vertebrate brains, and the degree to which the dorsal surface of the latter has expanded during evolution. As to scale, and in contrast with the situation in vertebrates, a larval neuron in amphioxus can be quite dorsal in relative terms and still be only a few cell diameters from the ventral midline and floor plate. With the addition of an expanded set of dorsal brain structures in vertebrates, cells and cell groupings that were originally quite dorsal will become progressively ventral in relative terms so long as their point of origin along the dorsoventral axis of the ependymal layer is ventral to the expansion zone. Hence there is no contradiction in supposing that dorsally positioned DA neurons belonging to Population 1 could have homologs in laterally- or ventrally-positioned nuclei in vertebrates. It is also worth noting that the close association of the anterior-most amphioxus pDA (PIN1) neurons with the floor plate in young larvae accords with evidence that the vertebrate floor plate is a source of DA progenitors (e.g. Bonilla et al., 2008).

A second, and more fundamental, problem is to determine whether the organization of the DA system in amphioxus has anything useful to tell us about the distribution of DA neurons across different brain regions in ancestral chordates, and hence in vertebrates, or whether secondary alterations have changed the organization of the amphioxus dien-mesencephalon to the point that no meaningful phylogenetic information can be extracted from it. It may well be that absence of two key organizers in amphioxus, the zona limitans intrathalamicaand the isthmus organizer, has allowed rostral structures originally restricted by an ancestral diencephalic domain to spread caudally and displace or otherwise alter a domain that was originally more midbrain-like. If so, the extension of both the lamellar body and the DA system to the end of somite 1 is probably secondary rather than ancestral, and the mesencephalic DA centers of amniotes would be evolutionary innovations.

The alternative is to see the dien-mesencephalon as an ancestral feature preserved in amphioxus. Further, because the dien-mesencephalon is co-extensive with the domain bounded by the zona limitans intrathalamica and isthmic organizer, the dienmesencephalon counterpart in hemichordates can be identified as lying between the latter two signaling centers. The resulting phylogeny (Fig. 7) clearly shows evolutionary continuity in the positioning of $\mathrm{TH}+$ and DA neural centers from basal deuterostomes to vertebrates. The extended distribution of DA neurons through the whole domain in amphioxus, assuming this reflects the ancestral condition, provides, in principle, sufficient precursors over an extended distance for the evolutionary elaboration of both diencephalic and mesencephalic DA centers in vertebrates. The absence of the latter in lampreys and teleosts would then be due to secondary loss, which is plausible, given that midbrain DA populations are present in elasmobranchs (Carrera et al., 2012).

In this context, it is a meaningful exercise to try to determine where, within the combined domain in amphioxus, a transition occurs between structures and cell types that map to the diencephalon and those that map to the midbrain. Chief among the latter is the PMC, a plausible homolog of the vertebrate MLR, which implies that the mesencephalic part of the amphioxus dien-mesencephalon begins at least as far forward as the PMC. Further, since the diencephalon does not give rise to motor nerves, the anterior-most of these in amphioxus, located about $20 \mu \mathrm{m}$ forward of the boundary between

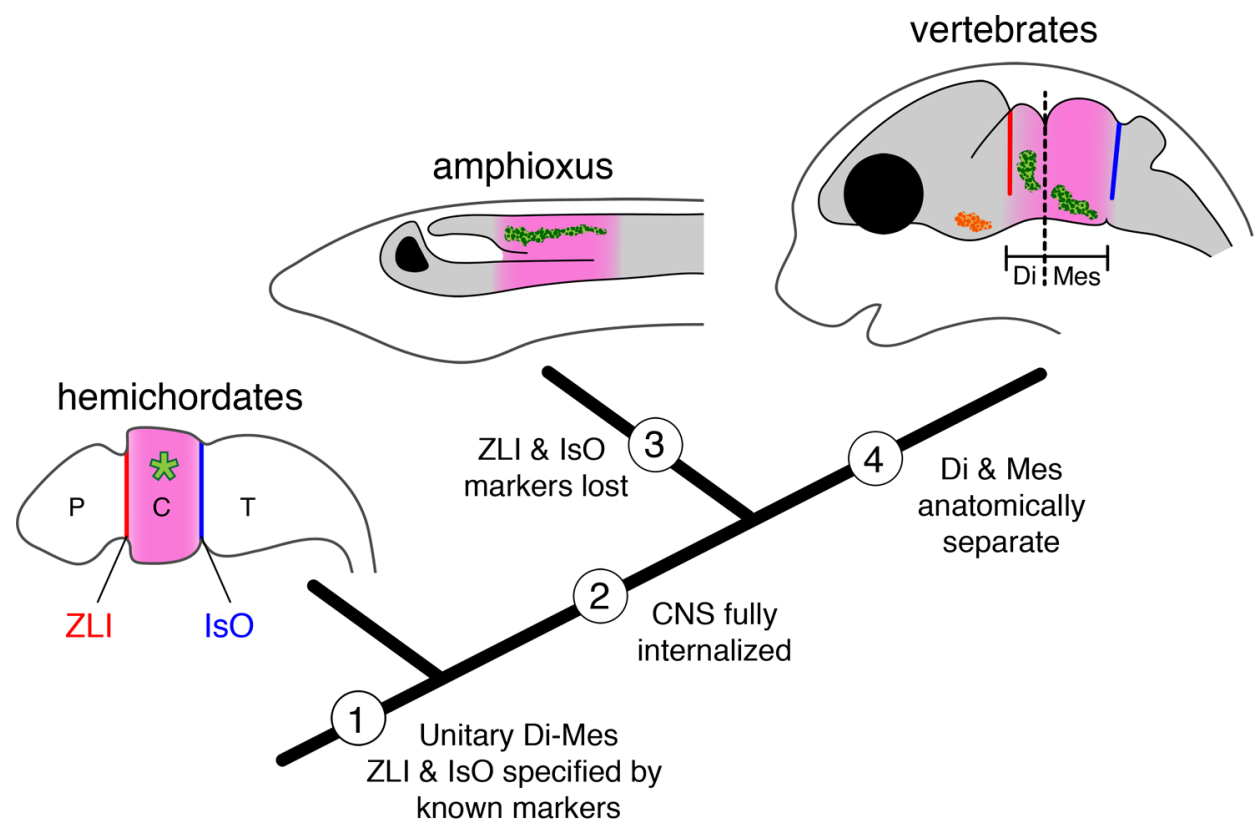

Fig. 7. Evolutionary continuity of dienmesencephalic tyrosine hydroxylase (TH)+ neurons in deuterostomes. A comparison of comparable neural domains in developing stages of a hemichordate, amphioxus, and an amniote vertebrate, showing that the domain defined as lying between the zona limitans intrathalamica (ZLI, vertical red line) and isthmic organizer (IsO, vertical blue line) or, for hemichordates, their homologs, corresponds with the dien-mesencephalon (DiMes) (shown in pink) of Albuixech-Crespo et al. (2017), which is also where populations of $D A$ and $T H+$ neurons reside. Hemichordates have an intraepithelial nervous system, but Pani et al. (2012) have shown that the same genetic markers that define this domain in the vertebrate brain do so as well in hemichordates, and that it corresponds to the collar (C). The zone in question is a site of $\mathrm{TH}+$ and DAergic neuronal populations according to Pani et al. (2012) for hemichordates, and this account and Moretetal. (2004) for amphioxus. In vertebrates, reviewed by Yamamoto and Vernier (2011), there are DA nuclei in both the mesencephalic (Mes) and caudal diencephalic (Di) parts of the brain, and in the hypothalamus, though this varies between taxa. Here, TH+ and DA cell groupings associated with the Di-Mes are shown in green, though in hemichordates (green asterisk) their precise location has not been described. There is currently no evidence in amphioxus for homologs of vertebrate hypothalamic DA nuclei (orange), but if these are ancient features of deuterostomes, they might also be present in hemichordates. If so, their expected location would be anterior to the ZLI, i.e. in the proboscis. It is not currently clear whether the absence of a fully internalized CNS in hemichordates is a secondary simplification, or reflects the ancestral condition, with internalization occurring early in the chordate lineage as shown here. Abbreviations: 1-4, character states; C, collar; CNS, central nervous system; Di, diencephalon; Di-Mes, dien-mesencephalon; IsO, isthmic organizer; Mes, mesencephalon; P, proboscis; T, trunk; ZLI, zona limitans intrathalamica. 
somites 1 and 2 in 12-day B. floridae larvae, should also be mesencephalic. The lamellar body expands caudally beyond this point in late stage larvae (e.g. see Fig. 12, in Lacalli 2002), which prompts us to suggest that some of this increase in size may be to meet a functional demand. The sizeable mass of close-packed lamellae of which the lamellar body is composed implies that monitoring day length, its supposed function, requires maximal sensitivity to very low light levels. Expanding caudally into adjacent CNS domains to achieve greater size and light-gathering ability might then be advantageous, but would compromise the value of the lamellar body as marker of any one CNS domain.

In summary, our observations, together with those of Moret et al. (2004), accord with the molecular data of Albuixech-Crespo et al. (2017) in identifying a domain extending from the front of the lamellar body to the end of somite 1 that is both the exclusive site in which dorsal DA (i.e. Population 1) and pDA neurons are found, and which also expresses molecular markers characteristic of the dien-mesencephalon as defined by the latter authors. So long as this unified domain reflects the ancestral condition rather then being secondarily derived, the DA neurons of Population 1 span a sufficient anteroposterior distance by the adult stage to provide progenitors to populate both brain regions. The most rostral neurons in Population 1 would then find their homologs among diencephalic nuclei (e.g. A11 and 13), while more caudal neurons would more likely have mesencephalic counterparts (A9 and 10). Our data unfortunately tell us nothing about the origin of more rostral DA nuclei, i.e. those located in the hypothalamus. However, considering the opportunism we observed during DA cell development in amphioxus, our analysis may explain one curious feature of the vertebrate DAsystem: that the caudal projections to the locomotory centers arise from A11, a diencephalic nucleus, whereas the more caudal midbrain nuclei project forward to telencephalic structures. One could argue that the anterior-most DA neurons have always, in chordates, played a key role in establishing the first locomotory control circuits, but once this is accomplished during development, later developing, more caudal DA neurons are free to participate in other circuits, including those supplying newly evolved and later developing structures, e.g. in the forebrain. We suggest this flexibility may be the key to understanding the role DA neurons play both evolutionarily and functionally in the vertebrate brain.

\section{Materials and Methods}

\section{Obtaining animals and embryos, and TH cDNA cloning}

Adult amphioxus ( $B$. lanceolatum) were collected in the bay of Argelèssur-Mer, France, gametes were obtained by thermal stimulation (Fuentes et al., 2004), and embryos and larvae were fixed as described by Candiani et al., (2015). Total RNA from $B$. lanceolatum adults was extracted using the TRIzol LS reagent (Invitrogen, USA) and treated with RNAse-free DNAse I (Ambion Europe Ltd., UK) according to the manufacturer's recommendations to digest genomic DNA. First-strand cDNA was synthesized with 5 $\mu \mathrm{g}$ of RNA using the SuperScript first-strand synthesis system (Invitrogen, USA) and oligo(dT) primers. Using the available sequence of the $B$. lanceolatum THgene (accession number: AJ577809), we designed the following primers to amplify, by PCR, a partial clone of the $B$. lanceolatum $\mathrm{TH}$ gene: 5'-TTCGATAGACTGCCCGCCATCTTG-3' and 5'-CTTGATTTCCGGCTTGCCAGACA-3'. The PCR product, with a length of $1063 \mathrm{bp}$, was directly cloned using a TOPO TA cloning kit (Invitrogen, USA) and subsequently verified by sequencing of both DNA strands using a PerkinElmer 377 Prism DNA Sequencer (PerkinElmer, USA) sequencing machine.

\section{Whole mount in situ hybridization and immunohistochemistry}

TH mRNA expression was assessed by in situ hybridization of $B$. lanceolatum embryos and larvae fixed at different developmental stages (Candiani et al., 2015). The partial B. lanceolatum TH clone obtained was used as template for the synthesis of antisense and sense riboprobes. After in situ hybridization, images were obtained using an Olympus IX71 microscope (Olympus Italia S.R.L., Italy) equipped with a chilled color digital camera, ColorView II (Soft Imaging System GmbH, Germany). Images were subsequently processed using the analySIS software package (Soft Imaging System GmbH, Germany).

For immunohistochemistry, fixed amphioxus larvae were washed several times with PBS (phosphate buffered saline, $0.1 \mathrm{M}, \mathrm{pH} 7.4$ ) for $1 \mathrm{~h}$ and then immersed in blocking buffer (PBS plus 0,3\% Triton X-100 and 1.5\% $\mathrm{BSA}$ ) for $1 \mathrm{~h}$. Larvae were then incubated in primary antibodies, anti-TH rabbit polyclonal antibody from Millipore (USA) (AB152) or anti-DA rabbit polyclonal antibody from Abcam (France) (ab8888) and anti-acetylated $\beta$ tubulin antibody from Sigma Aldrich (USA) (T6793). All primary antibodies were applied at a dilution of $1: 500$ in blocking buffer for $48 \mathrm{~h}$ at $4^{\circ} \mathrm{C}$. The specimens were then washed in several changes of PBS and incubated, at $4^{\circ} \mathrm{C}$ overnight, in the nucleic acid dye Hoechst/bisBenzimid from Invitrogen (USA) and in the secondary antibodies, anti-rabbit IgG Alexa Fluor ${ }^{\circledR} 488$ from Thermo Fisher Scientific (USA) (A-11008) and anti-mouse Суз ${ }^{\mathrm{TM}}$ from Bethyl Laboratories Inc. (USA) (A90-516C3). Hoechst was applied at a dilution of $1: 5000$, and the secondary antibodies at dilutions of 1:800 for anti-rabbit IgG Alexa Fluor ${ }^{\circledR} 488$ and 1:1500 for anti-mouse Cy $3^{\text {TM }}$. After several rinses with PBS, larvae were mounted in Mowiol (Sigma Aldrich, USA) and imaged using a Leica TCS SP5 confocal laser scanning microscope (Leica Microsystems, Germany).

\section{Transmission electron microscopy (TEM)}

For TEM, the principle subject was a single $300 \mathrm{hpf}$ (12-day) larva of $B$. floridae, prepared, serially sectioned, and reconstructed following methods described by Lacalli et al. (1994). The section series, described previously but re-examined here, extends from the front of the nerve cord to the end of somite 2. We also included TEM data from sections through a newly metamorphosed juvenile, sectioned at $2 \mu \mathrm{m}$ intervals through the first two somites, and prepared following the same methods.

\section{Filming larval swimming behavior}

B. lanceolatum larvae at either 27,30 or $72 \mathrm{hpf}$ were transferred into a Petri dish containing $2.5 \mathrm{ml}$ artificial seawater and left under a stereomicroscope to acclimatize for $10 \mathrm{~min}$. Larval swimming movements were then filmed at 200 frames/sec with a Hamamatsu Flash4 camera (Hamamatsu Photonics, Japan). The movies obtained were exported at 7 frames/sec using the ImageJ software (Schneider et al., 2012).

\section{Acknowledgments}

The authors are grateful to Hector Escriva from the Observatoire Océanologique de Banyuls-sur-Mer, France, for his support in collecting B. lanceolatum adults, Manuel Irimia and José Luis Ferran for discussions of relevant molecular data before publication, and Heather Down for assistance preparing figures. SC and MP were supported by a National Grant of the University of Genova and by ASSEMBLE (grant number 227799), TCL received funding from NSERC Canada and the Lionel G. Harrison Research Trust, and EZ was a Doctoral Fellow of the Studienstiftung der Deutschen Wirtschaft (SDW).

\section{References}

ABALO X M, VILLAR-CHEDA B, ANADÓN R, RODICIO M C (2005). Development of the dopamine-immunoreactive system in the central nervous system of the sea lamprey. Brain Res Bull 66: 560-564.

ALBUIXECH-CRESPOB, LOPEZ-BLANCHD, BURGUERAD, MAESOI, SANCHEZARRONESL, MORENO-BRAVOJA, SOMORJAII, PASCUAL-ANAYAJ, PUELLES 
E, BOVOLENTA P, GARCIA-FERNANDEZ J, PUELLES L, IRIMIA M, FERRAN $J \mathrm{~L}$ (2017). Molecular regionalization of the developing amphioxus neural tube challenges major partitions of the vertebrate brain. PLoS Biol, 15: e2001573.

BARRON, A B, SøVIK, E, CORNISH, J L (2010). The roles of dopamine and related compounds in reward-seeking behavior across animal phyla. Front Behav Neurosci 4: 163.

BAYLISS A L, EVANS P D (2013). Characterisation of AmphiAmR11, an amphioxus (Branchiostoma floridae) $\mathrm{D}_{2}$-dopamine-like $\mathrm{G}$ protein-coupled receptor. PLoS One 8: e80833.

BEN-JONATHAN N, HNASKO R (2001). Dopamine as a prolactin (PRL) inhibitor. Endocr Rev 22: 724-763.

BJÖRKLUND A, DUNNETT S B (2007). Dopamine neuron systems in the brain: an update. Trends Neurosci 30: 194-202.

BONILLAS, HALLA C, PINTO L, ATTARDO A, GÖTZ M, HUTTNER W B, ARENAS E (2008). Identification of midbrain floor plate radial glial-like cells as dopaminergic progenitors. Glia 56: 809-820.

BORODINSKY L N, BELGACEM Y H (2016). Crosstalk among electrical activity, trophic factors and morphogenetic proteins in the regulation of neurotransmitter phenotype specification. J Chem Neuroanat 73: 3-8.

BURMAN C, EVANS P D (2010). Amphioxus expresses both vertebrate-type and invertebrate-type dopamine $D(1)$ receptors. Invert Neurosci 10: 93-105.

CALLIER S, SNAPYAN M, LE CROM S, PROU D, VINCENT J D, VERNIER P (2003). Evolution and cell biology of dopamine receptors in vertebrates. Biol Cell 95: 489-502.

CANDIANI S, OLIVERI D, PARODI M, CASTAGNOLA P, PESTARINO M (2005). AmphiD1/ $\beta$, a dopamine D1/ $\beta$-adrenergic receptor from the amphioxus Branchiostoma floridae: evolutionary aspects of the catecholaminergic system during development. Dev Genes Evol 215: 631-638.

CANDIANI S, MORONTI L, RAMOINO P, SCHBERT M, PESTARINO M (2012). A neurochemical map of the developing amphioxus nervous system. BMC Neurosci 13: 59.

CANDIANI S, GARBARINO G, PESTARINO M (2015). Detection of mRNA and microRNA expression in basal chordates, amphioxus and ascidians. Neuromethods 99: 279-292.

CARRERA I, ANADÓN R, RODRÍGUEZ-MOLDES I (2012). Development of tyrosine hydroxylase-immunoreactive cell populations and fiber pathways in the brain of the dogfish Scyliorhinus canicula: new perspectives on the evolution of the vertebrate catecholaminergic system. J Comp Neurol 520: 3574-3603.

CASTRO L F, RASMUSSEN S L, HOLLAND P W, HOLLAND N D, HOLLAND L Z (2006). A Gbx homeobox gene in amphioxus: insights into ancestry of the ANTP class and evolution of the midbrain/hindbrain boundary. Dev Biol 295: 40-51.

DAUBNER S C, LE T, WANG S (2011). Tyrosine hydroxylase and regulation of dopamine synthesis. Arch Biochem Biophys 508: 1-12.

EKSTRÖM P, HONKANENT, BORG B (1992). Development of tyrosine hydroxylase-, dopamine- and dopamine $\beta$-hydroxylase-immunoreactive neurons in a teleost, the three-spined stickleback. J Chem Neuroanat 5: 481-501.

FUENTES M, SCHUBERT M, DALFO D, CANDIANI S, BENITO E, GARDENYES J, GODOY L, MORET F, ILLAS M, PATTEN I, PERMANYER J, OLIVERI D, BOEUF G, FALCON J, PESTARINO M, GARCIA-FERNANDEZ J, ALBALAT R, LAUDET V, VERNIER P, ESCRIVA H (2004). Preliminary observations on the spawning conditions of the European amphioxus (Branchiostoma lanceolatum) in captivity. $J$ Exp Zool B: Mol Dev Evol 302: 384-391.

HIROSHIMA Y, MIYAMOTO H, NAKAMURA F, MASUKAWA D, YAMAMOTO T, MURAOKA H, KAMIYA M, YAMASHITA N, SUZUKI T, MATSUZAKI S, ENDO I, GOSHIMA Y (2014). The protein Ocular albinism 1 is the orphan GPCR GPR143 and mediates depressor and bradycardic responses to DOPA in the nucleus tractus solitarii. Br J Pharmacol 171: 403-414.

HOLLAND L Z (2015). Genomics, evolution and development of amphioxus and tunicates: the Goldilocks principle. J Exp Zool B: Mol Dev Evol 324: 342-352.

HOLLAND L Z, HOLLAND N D (1999). Chordate origins of the vertebrate central nervous system. Curr Opin Neurobiol 9: 596-602

HOLLAND L Z, CARVALHO J E, ESCRIVA H, LAUDET V, SCHUBERT M, SHIMELD S M, YU J K (2013). Evolution of bilaterian central nervous systems: a single origin? EvoDevo 4: 27.

LACALLI T C (2000). Cell morphology in amphioxus nerve cord may reflect the time course of cell differentiation. Int J Dev Biol 44: 903-906.

LACALLI T C (2002). Sensory pathways in amphioxus larvae I. Constituent fibres of the rostral and anterodorsal nerves, their targets and evolutionary significance. Acta Zool 83: 149-166.

LACALLI T C (2017). Interpreting amphioxus, and thoughts on ancestral chordate mouths and brains. Int J Dev Biol 61: 649-654.

LACALLITC, KELLYSJ (2003). Ventral neurons in the anterior nerve cord of amphioxus larvae I. An inventory of cell types and synaptic patterns. J Morph 257: 190-211.

LACALLI T C, CANDIANI S (2017). Locomotory control in amphioxus larvae: new insights from neurochemical data. EvoDevo 8: 4.

LACALLI T C, HOLLAND N D, WEST J E (1994). Landmarks in the anterior nervous system of amphioxus larvae. Phil Trans $R$ Soc B 344: 165-185.

LOPEZ V M, DECATUR C L, STAMER W D, LYNCH, R M, MCKAY, B S (2008). LDOPA is an endogenous ligand for OA1. PLoS Biol 6: e236.

MISU Y, KITAHAMA K, GOSHIMA Y (2003). L-3, 4-Dihydroxyphenylalanine as a neurotransmitter candidate in the central nervous system. Pharmacol Ther97:117-137.

MISU Y, GOSHIMA Y (2006). Neurobiology of DOPA as a neurotransmitter. CRC Press, Boca Raton.

MORET F, GUILLAND J C, COUDOUEL S, ROCHETTE L, VERNIER P (2004). Distribution of tyrosine hydroxylase, dopamine and serotonin in the central nervous system of amphioxus (Branchiostoma lanceolatum): implications for the evolution of catecholamine systems in vertebrates. J Comp Neurol 468: 135-150.

O'CONNELLLA, HOFMANNHA(2011). The vertebrate mesolimbic reward system and social behavior network: a comparative synthesis. J Comp Neurol519:3599-3639.

PANI A M, MULLARKEY E E, ARONOWICZ J, ASSIMACOPOULOS S, GROVE E A, LOWE C J (2012). Ancient deuterostome origins of vertebrate brain signalling centres. Nature 483: 289-294.

RYAN K, LU Z, MEINERTZHAGEN I A (2016). The CNS connectome of a tadpole larva of Ciona intestinalis highlights sidedness in the brain of a chordate sibling. elife 5: e16962.

RYAN K, LU Z, MEINERTZHAGEN I A (2017). Circuit homology of decussating pathways in the Ciona larval CNS and the vertebrate startle-response pathway. Curr Biol 27: 721-728.

RYCZKO D, GRÄTSCH S, AUCLAIR F, DUBÉ C, BERGERON S, ALPERT M H, CONE J J, ROITMAN M F, ALFORD S, DUBUC R (2013). Forebrain dopamine neurons project down to a brainstem region controlling locomotion. Proc NatAcad Sci USA 110: E3235-E3242.

SCHNEIDER C A, RASBAND W S, ELICEIRI K W (2012). NIH Image to ImageJ: 25 years of image analysis. Nat Methods 9: 671-675.

SMEETSWJ, GONZÁLEZA(2000). Catecholamine systems in the brain of vertebrates: new perspectives through a comparative approach. Brain Res Rev 33: 308-379.

SOLANO F (2014) Melanins: skin pigments and much more-types, structural models, biological functions, and formation routes. New J Sci 2014: 1-28.

SIROTA M G, DI PRISCO G V, DUBUC R (2000). Stimulation of the mesencephalic locomotor region elicits controlled swimming in semi-intact lampreys. Eur J Neurosci 12: 4081-4092.

STOKES M D (1997). Larval locomotion of the lancelet Branchiostoma floridae. J Exp Biol 200: 1661-1680.

UGRUMOV M (2013). Brain neurons partly expressing dopamine phenotype: location, development, functional significance, and regulation. Adv Pharmacol 68: 37-91.

WICHT H, LACALLI T C (2005). The nervous system of amphioxus: structure, development, and evolutionary significance. Can J Zool 83: 122-150.

YAMAMOTO K, VERNIERP (2011). The evolution of dopamine systems in chordates. Front Neuroanat 5: 21 


\section{Further Related Reading, published previously in the Int. J. Dev. Biol.}

From the American to the European amphioxus: towards experimental Evo-Devo at the origin of chordates Jordi Garcia-Fernàndez, Senda Jiménez-Delgado, Juan Pascual-Anaya, Ignacio Maeso, Manuel Irimia, Carolina Minguillón, Èlia BenitoGutiérrez, Josep Gardenyes, Stéphanie Bertrand and Salvatore D'Aniello Int. J. Dev. Biol. (2009) 53: 1359-1366 https://doi.org/10.1387/ijdb.072436jg

Evolution of CUT class homeobox genes: insights from the genome of the amphioxus, Branchiostoma floridae Naohito Takatori and Hidetoshi Saiga Int. J. Dev. Biol. (2008) 52: 969-977

https://doi.org/10.1387/ijdb.072541nt

Peter Holland, homeobox genes and the developmental basis of animal diversity Sebastian M. Shimeld

Int. J. Dev. Biol. (2008) 52: 3-7

https://doi.org/10.1387/ijdb.072394ss

Developmental expression of the High Mobility Group B gene in the amphioxus, Branchiostoma belcheri tsingtauense

Xiangwei Huang, Lifeng Wang and Hongwei Zhang

Int. J. Dev. Biol. (2005) 49: 49-46

http://www.intjdevbiol.com/web/paper/041915xh

Cell morphology in amphioxus nerve cord may reflect the time course of cell differentiation T C Lacalli

Int. J. Dev. Biol. (2000) 44: 903-906

http://www.intjdevbiol.com/web/paper/11206331

Embryonic development of heads, skeletons and amphioxus: Edwin S. Goodrich revisited P W Holland

Int. J. Dev. Biol. (2000) 44: 29-34

http://www.intjdevbiol.com/web/paper/10761843

Amphioxus Hox genes: insights into evolution and development

$\mathrm{J}$ Garcia-Fernàndez and $\mathrm{P}$ W Holland

Int. J. Dev. Biol. (1996) 40: S71-S72

http://www.intjdevbiol.com/web/paper/9087701

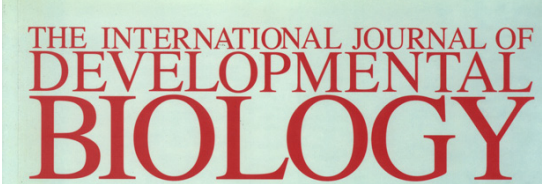

5 yr ISI Impact Factor $(2013)=2.879$
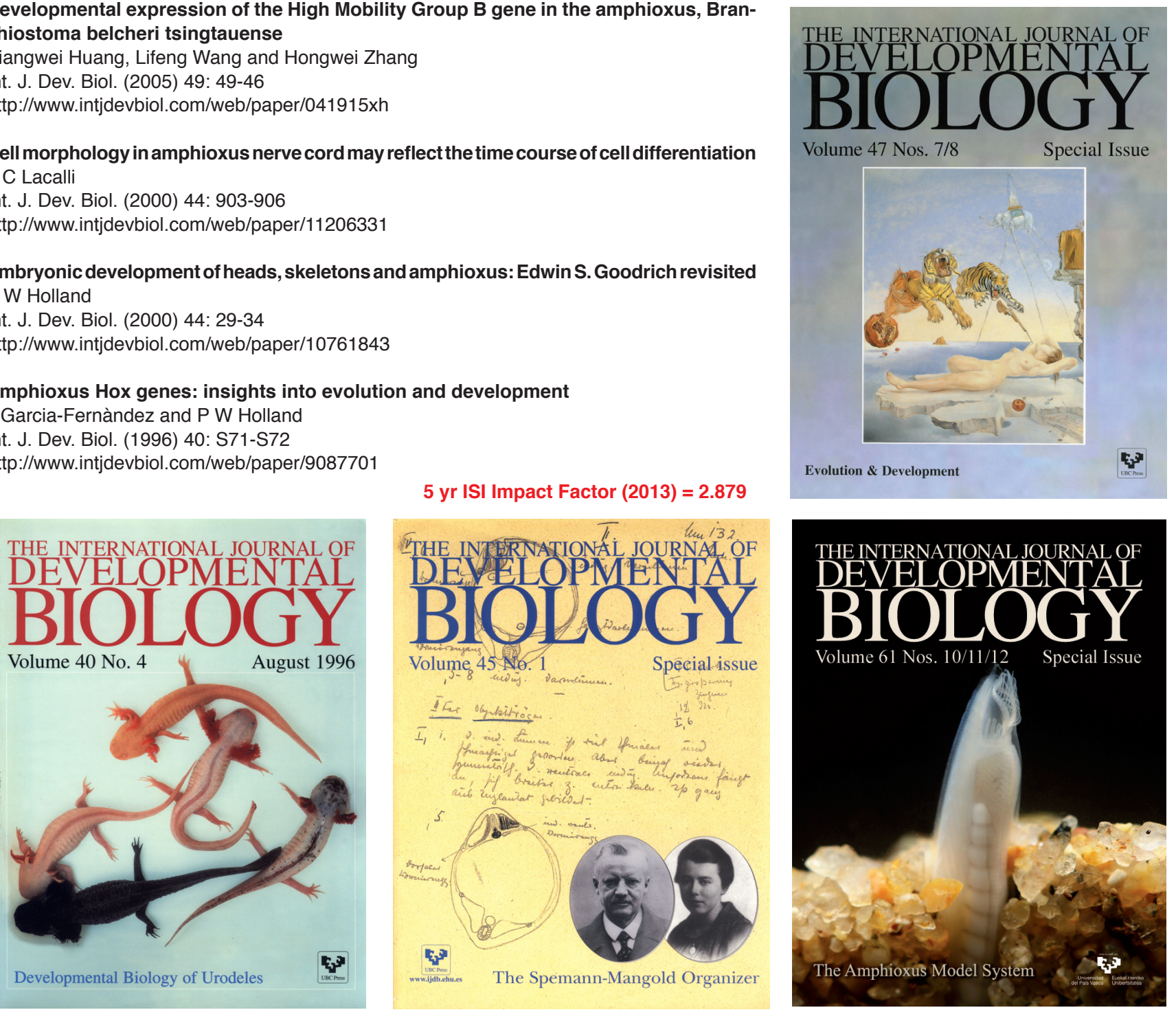